\title{
Análise facial numérica do perfil de brasileiros Padrão I
}

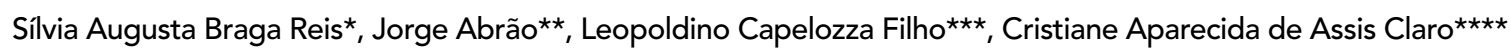

\section{Resumo}

Objetivo: o objetivo do presente estudo foi determinar as medidas do perfil facial de brasileiros portadores de equilíbrio facial, denominados Padrão I. Metodologia: a amostra foi constituída por 50 indivíduos (32 femininos e 18 masculinos), brasileiros, adultos, leucodermas, com idade média de 23 anos. Fotografias padronizadas do perfil foram obtidas. Sobre essas foram executados os traçados por dois avaliadores, que verificaram: 1) ângulo nasolabial; 2) ângulo mentolabial; 3) ângulo interlabial; 4) ângulo de convexidade facial; 5) ângulo de convexidade facial total; 6) ângulo do terço inferior da face; 7) proporção entre a altura facial anterior média e a altura facial anterior inferior e 8) proporção do terço inferior da face. Resultados e Conclusões: não houve diferença estatística relevante entre as duas medidas realizadas. Os valores de média, desvio-padrão, valores máximos e mínimos obtidos para cada variável estudada foram: 1) ângulo nasolabial: $108,13^{\circ} \pm 9,75^{\circ}\left(81^{\circ}\right.$ a $\left.127^{\circ}\right)$; 2) ângulo do sulco mentolabial: $132,37^{\circ} \pm 9,82^{\circ}\left(110,5^{\circ}\right.$ a $\left.152^{\circ}\right)$; 3) ângulo interlabial: $135,35^{\circ} \pm 11,14^{\circ}$ $\left(116,5^{\circ}\right.$ a $\left.159,5^{\circ}\right)$; 4 ) ângulo de convexidade facial: $12,32^{\circ} \pm 3,93^{\circ}$ ( $4^{\circ}$ a $\left.19,5^{\circ}\right)$; 5 ) ângulo de convexidade facial total: $137,85^{\circ} \pm 4,08^{\circ}\left(129,5^{\circ}\right.$ a $\left.147,5^{\circ}\right)$; 6$)$ ângulo do terço inferior da face: $103,41^{\circ} \pm 8,12^{\circ}\left(88^{\circ}\right.$ a $\left.124^{\circ}\right)$; 7$)$ proporção entre os terços médio e inferior da face: $0,93 \pm 0,10(0,80$ a 1,21$)$ e 8$)$ proporção do terço inferior da face: $0,45 \pm 0,06(0,30$ a 0,67). Propõe-se esse conjunto de medidas como um padrão de referência para avaliação facial numérica de adultos, brasileiros, brancos.

Palavras-chave: Diagnóstico. Fotografias extrabucais. Análise facial. Perfil.

\section{INTRODUÇÃO}

Desde o início da Ortodontia, autores como Angle ${ }^{1}$, Case $^{6}$, Hellmann $^{8}$ e Wuerpel ${ }^{23}$ valorizaram a análise facial como um recurso indispensável para o adequado diagnóstico e o sucesso do tratamento ortodôntico. Ao utilizarem a avaliação subjetiva para elegerem faces representativas do ideal de beleza, como a de Apolo Belvedere, estes autores tentavam estabelecer parâmetros de normalidade a serem conquistados com o tratamento ortodôntico.

O advento da cefalometria desviou a atenção da face para a posição do esqueleto e dos dentes, permitindo o estabelecimento de referências de normali-

* Doutoranda em Ortodontia pela USP - São Paulo. Mestre em Ortodontia pela Universidade Metodista de São Paulo. Especialista em Ortodontia pela PROFIS - USP - Bauru. Professora Assistente do Departamento de Ortodontia da Universidade Metodista de São Paulo.

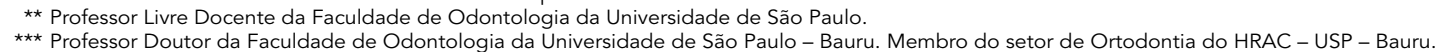

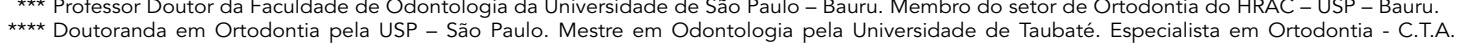

Professora Colaboradora Assistente da Disciplina de Ortodontia do Departamento de Odontologia da Universidade de Taubaté. 
dade mensuráveis. Iniciou-se um período de grande conforto para os ortodontistas, dispensados de usar a subjetividade, e grandes frustrações a alguns pacientes, que viam suas metas cefalométricas serem obtidas às custas de prejuízos na estética facial. Esse paradoxo exigiu, então, o reconhecimento da necessidade do uso dos parâmetros faciais no diagnóstico, por meio da análise morfológica da face.

A análise morfológica da face, nas vistas frontal e lateral, permite a definição do Padrão Facial em I, II, III, Face Longa e Face Curta, que remete a protocolos de tratamento e prognósticos específicos nas diferentes faixas etárias ${ }^{5}$.

O indivíduo Padrão I caracteriza-se pela normalidade nas relações esqueléticas sagitais e verticais, nas avaliações de frente e perfil ${ }^{5}$.

$\mathrm{Na}$ análise morfológica frontal, os portadores de Padrão I apresentam simetria aparente, distância intercantos medial dos olhos similar à largura do nariz, distância interpupilar similar à largura da comissura bucal, proporção entre os terços faciais, parte superior do terço inferior da face (altura do lábio superior) equivalente à metade da altura da parte inferior (lábio inferior e mento), volume proporcional de vermelhão dos lábios e selamento labial passivo, o qual pode estar comprometido nos pacientes acometidos por protrusão do arco dentário superior ${ }^{5}$.

$\mathrm{Na}$ avaliação do perfil, a normalidade é caracterizada por um grau moderado de convexidade. A expressão da maxila na face é identificada pela presença da projeção zigomática e depressão infraorbitária, que podem ser verificadas também na vistas frontal. A linha de implantação do nariz, levemente inclinada para anterior, denota adequada posição maxilar. O sulco naso-geniano com leve inclinação posterior completa a avaliação do equilíbrio maxilar. O ângulo nasolabial avalia a relação da base nasal em relação ao lábio superior, cuja posição é fortemente determinada pela inclinação dos incisivos superiores. Portanto, esse ângulo pode estar adequado, aberto ou fechado nos pacientes Padrão I, como conseqüência da posição dos dentes anteriores superiores, independente do bom posicionamento maxilar, sempre observado nestes pacientes ${ }^{5}$.

O equilibrio mandibular (tamanho, forma e posição) pode ser verificado na avaliação do perfil, por meio da linha queixo-pescoço. Ela deve ser expressiva sem ser excessiva e tender ao paralelismo com o plano de Camper. Esse paralelismo contribui para um ângulo adequado entre as linhas do queixo e do pescoço. Além disso, espera-se um ângulo mentolabial agradável esteticamente e construído com igual participação do lábio e do mento ${ }^{5}$.

Apesar das características acima citadas, que permitem o reconhecimento do indivíduo $\mathrm{Pa}$ drão I, diferentes configurações faciais podem ser observadas naqueles classificados como portadores desse Padrão. A variabilidade encontrada resulta das particularidades inerentes aos tipos faciais braquifacial, mesofacial e dolicofacial. As construções faciais obtidas, se pertencentes ao Padrão I, não são necessariamente belas, mas obrigatoriamente equilibradas nas suas mais diversas formas.

A má oclusão, quando presente nos indivíduos Padrão I, é decorrente de desarranjo dentário e confinada aos limites dentoalveolares, geralmente relacionado a fatores etiológicos ambientais, exceto nos pacientes com discrepâncias dente-osso positivas ou negativas. Ou seja, nos pacientes Padrão I o erro dentário é primário ou a essência da doença ${ }^{5}$, por isso mesmo inespecífico e dificilmente identificado pela análise facial do paciente. Esses pacientes não representam, portanto, grandes desafios para os ortodontistas, sendo, por esse motivo, pouco estudados.

Entendemos, entretanto, que os individuos $\mathrm{Pa}$ drão I são a referência de normalidade para o estudo e tratamento dos Padrões II, III, Face longa e Face Curta. Em artigo já publicado, estabelecemos as características cefalométricas dos indivíduos $\mathrm{Pa}$ drão $\mathrm{I}^{18}$. O objetivo deste estudo foi determinar as medidas para Análise Facial Numérica do Perfil de brasileiros, adultos, brancos, previamente reconhecidos, por meio da análise facial subjetiva, como portadores de equilíbrio facial. 


\section{MATERIAL E MÉTODOS}

A amostra do presente estudo foi constituída por 50 indivíduos selecionados a partir de uma amostra pré-existente composta por 100 brasileiros, adultos, leucodermas, portadores de selamento labial passivo, sendo 50 do gênero masculino e 50 do feminino, com idade média de 23 anos e 7 meses, variando entre 18 e 36 anos $^{11,17}$. Nenhum dos pacientes foi submetido previamente a tratamento ortodôntico ou cirurgia plástica facial.

Todos os indivíduos que aceitaram participar da presente pesquisa assinaram um termo de consentimento que esclarecia sobre os objetivos do trabalho e os exames aos quais seriam submetidos. No termo de consentimento, os participantes autorizavam ainda a divulgação de suas fotografias faciais para fins de ensino e pesquisa.

Fotografias padronizadas da face, nas vistas frontal e lateral, foram obtidas ${ }^{11,17}$. Na análise morfológica frontal da amostra original, $85 \%$ dos pacientes foram Padrão I, 11\% Padrão II e 4\% Padrão III. $\mathrm{Na}$ mesma avaliação do perfil observou-se $50 \% \mathrm{~Pa}-$ drão I, 41\% Padrão II e 9\% Padrão III. Os 50 indivíduos classificados como portadores do Padrão I nas avaliações frontal e lateral, 32 do gênero feminino e 18 do masculino, compuseram a amostra do presente estudo. Na fotografia frontal, além do selamento labial passivo, esses pacientes apresentavam: 1) simetria aparente; 2) distância intercantos medial dos olhos similar à largura do nariz; 3) distância interpupilar similar à largura da comissura bucal; 4) proporção entre os terços faciais; 5) altura do lábio superior equivalente à metade da altura somada do lábio inferior e mento; e 6) volume proporcional de vermelhão dos lábios. Ao exame do perfil foram verificados: 1) perfil levemente convexo; 2) terços faciais proporcionais; 3) linha queixo-pescoço paralela ao plano de Camper; 4) sulco mentolabial normal, com igual participação do lábio e do mento e 5) projeção zigomática presente, caracterizada pela presença de depressão infra-orbitária e sulco naso-geniano.

A idade média e o desvio-padrão da amostra foram $23 \pm 3$ anos. Para o gênero feminino obser- vou-se média e desvio-padrão de $23 \pm 2,9$ anos, enquanto para o gênero masculino os valores encontrados foram $23 \pm 3,4$ anos.

As fotografias do perfil foram traçadas e medidas por dois examinadores. Para avaliação do erro de medidas interexaminadores utilizou-se o Erro Padrão Percentual (EPP) (Tab. 1). Esse erro identifica a diferença percentual média obtida entre as medidas dos dois observadores. Considerando a variabilidade individual na marcação dos pontos, esperam-se maiores diferenças que nas avaliações intra-examinador. Entretanto, as porcentagens ficaram entre $1,14 \% \mathrm{e}$ $2,14 \%$ para os ângulos nasolabial, interlabial, mentolabial, de convexidade facial total e do terço inferior da face. Todas as medidas citadas apresentam médias que ultrapassam os $100^{\circ}$, indicando que o erro médio foi entre $1^{\circ} \mathrm{e} 2^{\circ}$, clinicamente insignificantes. Para as proporções AFAM/AFAI e do terço inferior da face, os EPPs foram respectivamente 4,49\% e 10,04\%. Erros maiores para essas medidas são esperados, uma vez que as proporções dependem de duas medidas distintas para cada observador, aumentando a chance do erro. Entretanto, o erro médio foi de 0,04 para as duas variáveis, valor clinicamente imperceptível. O maior EPP obtido foi para o ângulo de convexidade facial. Considerando que o valor médio para esse ângulo foi aproximadamente $12^{\circ}, 1$ grau de diferença nas medidas realizadas pelos 2 observadores, decorrentes de pequenas variações do traçado ou da capacidade de precisão do transferidor, já representam 8,33\% de EPP. Dificilmente, medidas realizadas por 2 observadores em 2 traçados diferentes ficariam aquém do 1 grau descrito acima.

Após a demarcação dos pontos tegumentares, realizamos a análise denominada Facial Numérica do Perfil, utilizando as seguintes grandezas:

1) Ângulo Nasolabial (Cm.Sn.Ls) - ângulo formado pela base do nariz e pelo lábio superior. Scheidemann et al. ${ }^{19}$ propuseram um valor normativo de $111,9^{\circ} \pm 8,4^{\circ}$ para o gênero feminino e $111,4^{\circ} \pm 11,7^{\circ}$ para o gênero masculino.

2) Ângulo do Sulco Mentolabial (Li.Lm.Pg') ângulo formado entre o lábio inferior e a projeção 
Tabela 1 - Valores médios obtidos nas medidas 1 e 2 das variáveis da Análise Facial Numérica do Perfil, com o Erro Padrão Percentual, o Intervalo de Confiança e os Intervalos de Confiança mínimo e máximo.

\begin{tabular}{|c|c|c|c|c|c|c|}
\hline variáveis & medida 1 & medida 2 & EPP* & IC** & $-I C^{* * *}$ & $+1 C^{* * * *}$ \\
\hline ângulo nasolabial & $108,13^{\circ}$ & $108,51^{\circ}$ & $2,14 \%$ & $0,81 \%$ & $1,32 \%$ & $2,95 \%$ \\
\hline ângulo mentolabial & $132,37^{\circ}$ & $131,72^{\circ}$ & $1,97 \%$ & $0,71 \%$ & $1,26 \%$ & $2,69 \%$ \\
\hline ângulo interlabial & $135,35^{\circ}$ & $135,48^{\circ}$ & $1,89 \%$ & $0,79 \%$ & $1,10 \%$ & $2,69 \%$ \\
\hline ângulo convexidade facial & $12,32^{\circ}$ & $11,63^{\circ}$ & $13,92 \%$ & $4,68 \%$ & $9,25 \%$ & $18,60 \%$ \\
\hline $\begin{array}{l}\text { ângulo convexidade facial } \\
\text { total }\end{array}$ & $137,85^{\circ}$ & $138,38^{\circ}$ & $1,14 \%$ & $0,47 \%$ & $0,66 \%$ & $1,61 \%$ \\
\hline $\begin{array}{c}\text { ângulo do terço inferior } \\
\text { da face }\end{array}$ & $103,41^{\circ}$ & $102,65^{\circ}$ & $1,72 \%$ & $0,56 \%$ & $1,17 \%$ & $2,28 \%$ \\
\hline proporção AFAM/AFAI & 0,93 & 0,91 & $4,49 \%$ & $1,40 \%$ & $3,10 \%$ & $5,89 \%$ \\
\hline $\begin{array}{l}\text { proporção do terço infe- } \\
\text { rior da face }\end{array}$ & 0,45 & 0,45 & $10,04 \%$ & $5,20 \%$ & $4,84 \%$ & $15,24 \%$ \\
\hline
\end{tabular}

*Erro Padrão Percentual, ${ }^{* *}$ Intervalo de Confiança, ${ }^{* * *}$ Intervalo de Confiança Mínimo, ${ }^{* * * *}$ Intervalo de Confiança Máximo.

Tabela 2 - Valores médios, mínimos e máximos e desvios-padrão das grandezas da Análise Facial Numérica do Perfil dos indivíduos Padrão I $(\mathrm{n}=50)$.

\begin{tabular}{|c|c|c|c|c|}
\hline variáveis & média & mínimo & máximo & d.p. \\
\hline ângulo mentolabial & $132,37^{\circ}$ & $110,5^{\circ}$ & $152^{\circ}$ & $9,82^{\circ}$ \\
\hline ângulo interlabial & $135,35^{\circ}$ & $11,14^{\circ}$ & $116,5^{\circ}$ & $159,5^{\circ}$ \\
\hline ângulo convexidade facial & $12,32^{\circ}$ & $4^{\circ}$ & $19,5^{\circ}$ & $3,93^{\circ}$ \\
\hline proporção AFAM/AFAI & 0,93 & 0,80 & 1,21 & 0,10 \\
\hline proporção do terço inferior face & 0,45 & 0,30 & 0,67 & 0,06 \\
\hline
\end{tabular}

Tabela 3 - Valores médios e desvios-padrão das grandezas da Análise Facial Numérica do Perfil para os gêneros feminino e masculino $(n=50)$.

\begin{tabular}{|c|c|c|c|c|c|c|}
\hline variáveis & média $F$ & d.p. & média M & d.p. & $\mathbf{t}$ & $\mathbf{p}$ \\
\hline ângulo nasolabial & $108,69^{\circ}$ & $9,22^{\circ}$ & $107,14^{\circ}$ & $10,83^{\circ}$ & 0,42 & 0,672 \\
\hline ângulo mentolabial & $133,42^{\circ}$ & $10,13^{\circ}$ & $130,5^{\circ}$ & $9,23^{\circ}$ & 1,1 & 0,277 \\
\hline ângulo interlabial & $136,30^{\circ}$ & $11,96^{\circ}$ & $133,66^{\circ}$ & $9,59^{\circ}$ & 0,83 & 0,409 \\
\hline $\begin{array}{l}\text { ângulo convexidade } \\
\text { facial }\end{array}$ & $12,18^{\circ}$ & $4,15^{\circ}$ & $12,55^{\circ}$ & $3,62^{\circ}$ & $-0,51$ & 0,613 \\
\hline $\begin{array}{l}\text { ângulo convexidade } \\
\text { facial total }\end{array}$ & $137,80^{\circ}$ & $4,19^{\circ}$ & $137,94^{\circ}$ & $4^{\circ}$ & $-0,1$ & 0,921 \\
\hline $\begin{array}{l}\text { ângulo do terço } \\
\text { inferior da face }\end{array}$ & $100,37^{\circ}$ & $6,90^{\circ}$ & $108,8^{\circ}$ & $4^{\circ}$ & $-4,92$ & $<0,001 *$ \\
\hline $\begin{array}{c}\text { proporção AFAM/ } \\
\text { AFAI }\end{array}$ & 0,97 & 0,09 & 0,86 & 0,07 & 5,63 & $<0,001 *$ \\
\hline $\begin{array}{l}\text { proporção do terço } \\
\text { inferior da face }\end{array}$ & 0,45 & 0,06 & 0,45 & 0,05 & 0 & 0,99 \\
\hline
\end{tabular}

* Diferença estatisticamente significante ao nível de $1 \%$. 
anterior do mento. Seu valor normativo proposto é $124^{\circ} \pm 10^{\circ}$.

3) Ângulo Interlabial (Sn.Ls.Li.Lm) - ângulo formado entre os lábios superior e inferior. Determina o grau de protrusão labial. $\mathrm{O}$ valor médio encontrado por Morris ${ }^{13}$ foi $133,02^{\circ} \pm 10,95^{\circ}$.

4) Ângulo de Convexidade Facial (G.Sn.Pg') - suplemento do ângulo formado pela intersecção das linhas glabela-subnasal e subnasal-pogônio tecido mole. Seu valor normativo é $12^{\circ} \pm 4^{\circ}$.

5) Ângulo de Convexidade Facial Total (G.Pr. Pg') - ângulo formado pela intersecção das linhas glabela-ponta do nariz e ponta do nariz-pogônio tecido mole. O valor normativo proposto é $140,2^{\circ}$ $\pm 4,9^{\circ}$ para o gênero masculino e $138,9^{\circ} \pm 6,2^{\circ}$ para o gênero feminino ${ }^{3}$.

6) Ângulo do Terço Inferior da Face (Sn.Gn'. C) - ângulo formado entre as linhas subnasalgnátio tecido mole e gnátio tecido mole-cervical. O valor normativo proposto é $100^{\circ} \pm 7^{\circ}$.

7) Proporção entre a Altura Facial Anterior Média e a Altura Facial Anterior Inferior (AFAM/ AFAI) - proporção entre as distâncias glabelasubnasal e subnasal-mentoniano mole, projetadas na linha vertical verdadeira. $O$ padrão de normalidade proposto para essa proporção é $1 \pm 0,08$.

8) Proporção do Terço Inferior da Face - proporção entre as distâncias subnasal-estômio e estômio-mentoniano mole projetadas na linha vertical verdadeira. $\mathrm{O}$ valor de normalidade proposto para essa proporção é $0,5 \pm 0,1$.

A linha vertical verdadeira foi estendida a partir do componente vertical do apoio do násio tecido mole, presente no cefalostato. Quando posicionada, essa estrutura deve ser fixa à sua base horizontal, assumindo uma posição vertical satisfatória.

Obtidas as grandezas das variáveis, caracterizou-se, quantitativamente, a amostra total e os gêneros feminino e masculino com a média, os valores mínimo e máximo e o desvio-padrão de cada medida estudada (Tab. 2, 3). A presença de dimorfismo sexual foi avaliada pelo teste $t$ de Student, ao nível de significância de 1\% (Tab. 3).

\section{RESULTADOS E DISCUSSÃO}

Favorecido pela normalidade das relações esqueléticas sagitais e verticais, o paciente Padrão I é reconhecido por meio da análise morfológica da face, nas avaliações de frente e perfil, pelo equilíbrio. Essa vantagem, conferida pela genética e perpetuada pelo crescimento, resulta em um prognóstico favorável para a correção dos transtornos ortodônticos porventura existentes.

O equilibrio da face e do sorriso é a busca incessante da Ortodontia, no tratamento dos diferentes Padrões. Um parâmetro de normalidade que se transforme em objetivo de tratamento é necessário para guiar os aprendizes e permitir estudos dos desvios da normalidade dos pacientes discrepantes.

Esse parâmetro não deve, entretanto, ser obtido a partir de amostras portadoras de equilíbrio dentário ou esquelético, uma vez que vários estudos já realizados mostraram não haver correlação entre o padrão dento-esquelético e o perfil facial $14,7,14,20$.

O indivíduo Padrão I de cada raça, identificado pela análise morfológica da face de frente e perfil, representa o normal facial para a mesma. Suas medidas cefalométricas e os valores obtidos na análise numérica do perfil facial fornecem os padrões de normalidade, para comparação com grupos discrepantes dessa mesma população, permitindo quantificações mais realistas dos erros apresentados e oferecendo referências para correções na direção do normal do grupo ao qual o paciente pertence ${ }^{18}$.

Os números obtidos nas medidas do perfil facial não têm a capacidade de determinar se uma face é normal ou não. Isso já foi definido pela análise morfológica. Todos os valores obtidos para essa amostra são, portanto, adequados para os indivíduos, pois compõem faces equilibradas. A grande variabilidade de medidas obtidas, incluindo os valores máximos e mínimos, reforça a impossibilidade dos números expressarem forma.

\section{Ângulo nasolabial}

Para o ângulo nasolabial, a média e o desviopadrão obtidos foram $108,13^{\circ} \pm 9,75^{\circ}$, variando 
entre $81^{\circ}$ e $127^{\circ}$, valor este agudo quando comparado aos $112^{\circ}$ sugeridos como padrão de normalidade pela literatura norte-americana, sugerindo maior protrusão labial superior em brasileiros. Esse achado coincide com o trabalho ${ }^{15}$ realizado em brasileiros do estado de São Paulo, mas diverge de estudos ${ }^{12,16}$ realizados com amostras do sul do país, que apresentaram a média do ângulo próxima do padrão internacional.

Coincide com o achado desse trabalho a maior protrusão dos incisivos superiores observada na avaliação cefalométrica da amostra Padrão $\mathrm{I}^{18}$, uma vez que a inclinação do mesmo determina a protrusão do lábio superior.

Devemos salientar ainda a importância da inclinação da base do nariz na construção desse ângulo, pois observamos indivíduos portadores de medidas muito diferentes para o ângulo, sem grandes alterações da protrusão labial. Isso fica mais evidente nos sujeitos onde observamos os valores máximo e mínimo. Ambos são portadores de Padrão I, portanto têm o perfil equilibrado, e mesmo assim a medida do ângulo nasolabial é muito distante da média, devido a diferenças na inclinação da base nasal (Fig. 1).

Não foi observado dimorfismo nas medidas obtidas nos gêneros feminino e masculino.

\section{Ângulo do sulco mentolabial}

A média e o desvio-padrão do ângulo do sulco mentolabial foram $132,37^{\circ} \pm 9,82^{\circ}$, com o mínimo de $110,5^{\circ}$ e o máximo de $152^{\circ}$. Este valor foi significativamente maior que os $124^{\circ}$ sugeridos como padrão para leucodermas, indicando uma menor projeção do lábio inferior ou do mento, para brasileiros portadores de equilibrio facial.

Considerando a maior protrusão dos incisivos inferiores observada na amostra de brasileiros Padrão $\mathrm{I}^{18} \mathrm{e}$ em outro estudo ${ }^{10}$ que avaliou crianças portadoras de faces harmoniosas e oclusão normal, podemos concluir que o aumento do ângulo mentolabial é decorrência da menor projeção anterior do mento.

A miscigenação racial pode ser a explicação para os ângulos mais abertos observados entre os brasileiros da referida amostra, quando comparados aos das amostras norte-americanas. Sutter e Turley $^{21}$ confirmaram essa afirmação, ao observarem que amostras de indivíduos afro-americanos apresentavam esse ângulo mais aberto que amostras de norte-americanos leucodermas.

Salientamos ainda a importância de considerar que indivíduos Padrão I podem apresentar o ângulo do sulco mentolabial tão fechado quanto $110,5^{\circ}$ ou tão aberto quanto $152^{\circ}$, sem que esses valores este-
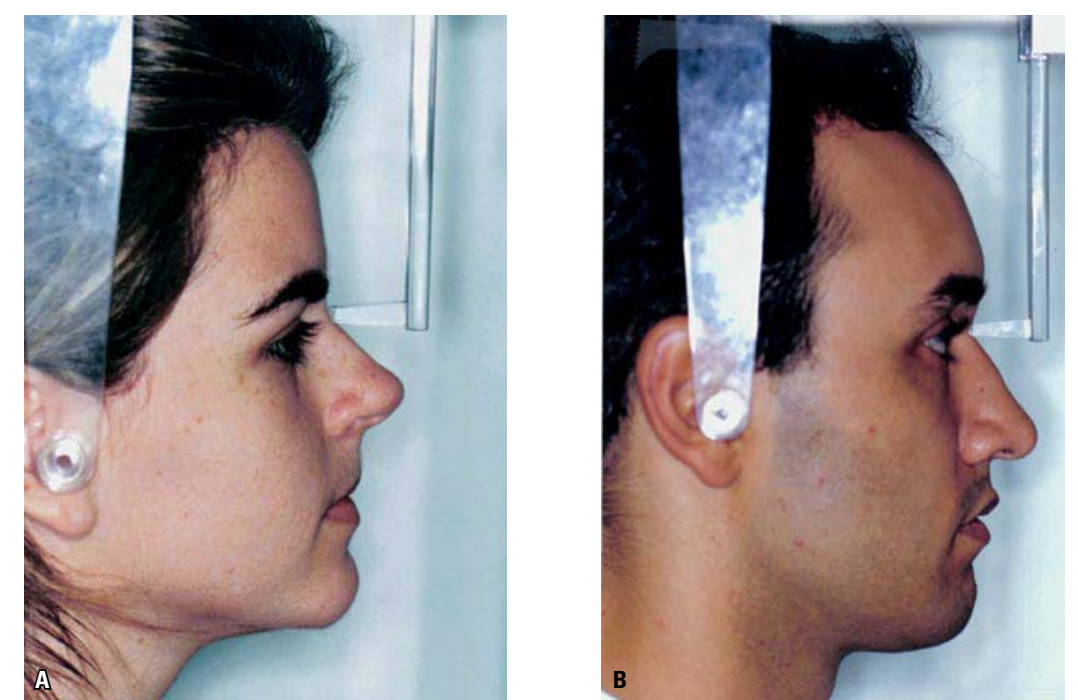

FIGURA 1 - Indivíduos Padrão I portadores do ângulo nasolabial A) máximo $\left(127,5^{\circ}\right)$ e B) mínimo $\left(80,5^{\circ}\right)$. Observa-se a grande diferença na inclinação da base nasal. 
jam associados a qualquer desequilíbrio na protrusão do lábio ou do mento. Ainda que não comprometam o equilibrio, os valores extremos observados podem estar associados a diferentes resultados estéticos. O ângulo do sulco mentolabial mínimo esteve presente em uma face esteticamente agradável, na qual os contornos do lábio inferior e do mento eram bem evidentes. $\mathrm{O}$ valor máximo obtido, entretanto, está associado a um terço inferior com contornos menos precisos, que não favorece a estética do perfil.

Não observamos dimorfismo entre as amostras masculina e feminina.

\section{Ângulo interlabial}

Os valores obtidos para o ângulo interlabial foram $135,35^{\circ} \pm 11,14^{\circ}$, sem dimorfismo sexual, variando entre $116,5^{\circ}$ e $159,5^{\circ}$, muito semelhante aos $133^{\circ}$ sugeridos como padrão para leucodermas caucasianos.

A medida encontrada para essa variável contrariou os achados anteriores, não demonstrando a maior protrusão labial sugerida pelas outras medidas para os indivíduos brasileiros Padrão I.

As diferenças observadas nas medidas dos ângulos nasolabial e mentolabial, além das obtidas em trabalho anterior para a inclinação dos incisi- vos superiores e inferiores ${ }^{18}$, sugerem que a protrusão dos lábios superior e inferior dos brasileiros Padrão I é diferente daquela observada nos leucodermas norte-americanos.

Entretanto, a similaridade no ângulo interlabial sugere que os lábios superior e inferior ${ }^{18}$ apresentam a mesma relação entre si nos leucodermas brasileiros e norte-americanos, variando suas relações com as estruturas adjacentes, ou seja, nariz para o lábio superior e mento para o inferior.

Deve-se ressaltar que apesar da maioria dos indivíduos Padrão I apresentar ângulo interlabial entre $124^{\circ}$ e $146^{\circ}$, pode-se observar medidas extremas como $116,5^{\circ}$ e $159,5^{\circ}$.

\section{Ângulo de convexidade facial}

$O$ ângulo de convexidade facial apresentou média de $12,32^{\circ} \pm 3,93^{\circ}$, sem dimorfismo sexual, coincidindo com os $12^{\circ}$ sugeridos como referência de normalidade por Legan e Burstone ${ }^{9}$.

Devemos observar, entretanto, que indivíduos Padrão I podem apresentar valores do ângulo de convexidade facial tão reduzidos como $4^{\circ}$ ou tão altos quanto $19,5^{\circ}$, sugerindo respectivamente perfis pouco e muito convexos. Pela classificação morfológica das faces, já verificamos que os valores obtidos
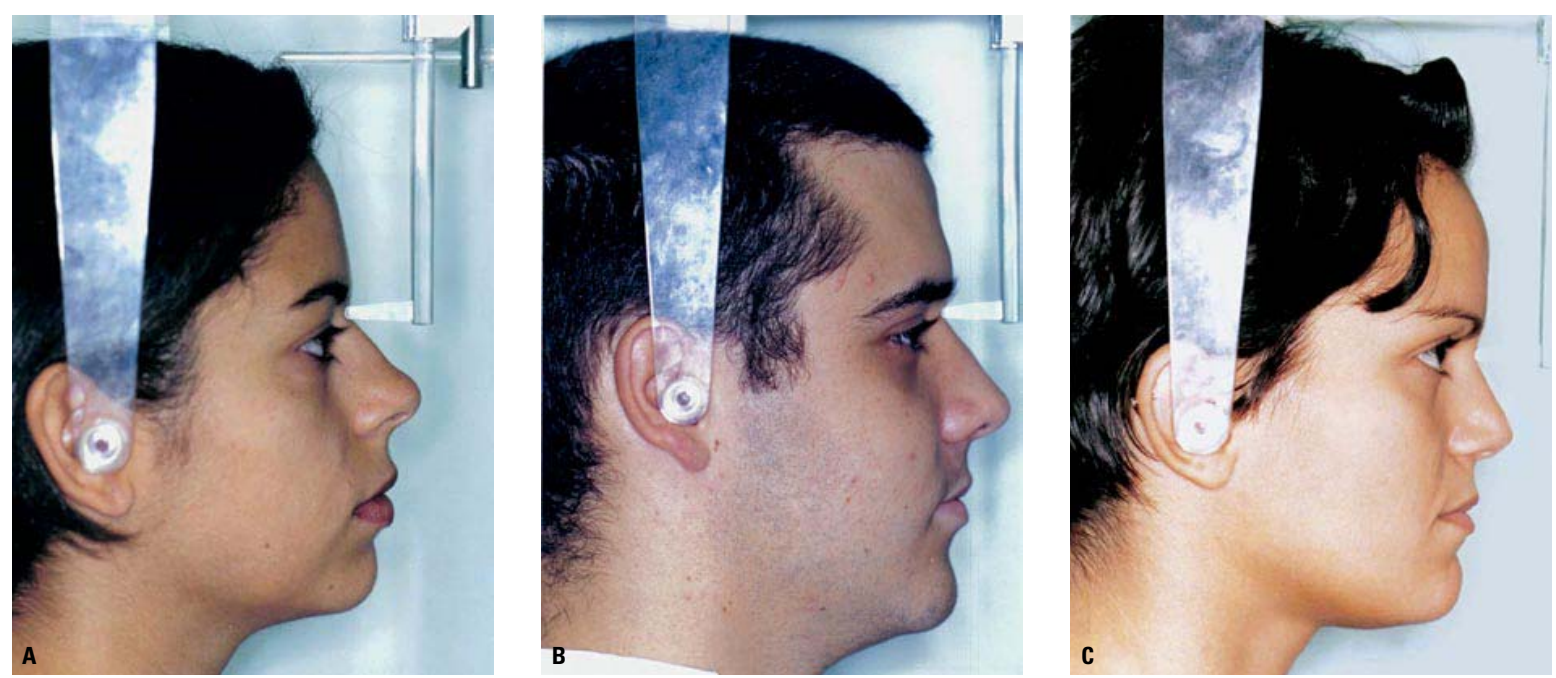

FIGURA 2 - Fotografias do perfil facial de indivíduos Padrão I portadores do ângulo de convexidade facial A) máximo $\left(19,5^{\circ}\right)$, B) coincidente com a média da amostra $\left(12^{\circ}\right)$ e C) mínimo $\left(4^{\circ}\right)$. 

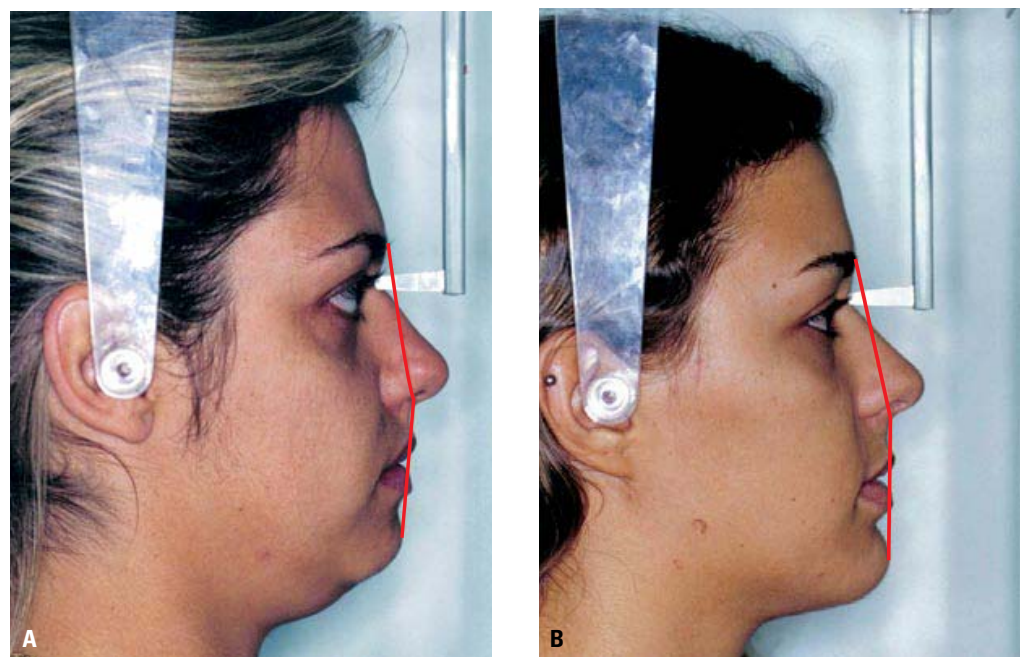

FIGURA 3 - Duas faces de indivíduos Padrão I portadores do mesmo valor do ângulo de convexidade facial $\left(13,5^{\circ}\right)$, mas diferentes em sua construção, sendo A) a primeira com maior projeção anterior da glabela e B) a segunda do mento.

não refletem a característica observada (Fig. 2).

Dois fatores devem ser considerados: o primeiro seria a influência da projeção anterior da glabela na determinação do valor do ângulo de convexidade facial. Uma maior ou menor projeção anterior da glabela pode resultar em uma abertura ou fechamento do ângulo. A figura 3 exemplifica duas faces portadoras do mesmo ângulo de convexidade facial $\left(13,5^{\circ}\right)$, mas diferentes em sua construção, sendo a primeira com maior projeção anterior da glabela e a segunda do mento.

O segundo fator é a influência do tipo facial na convexidade de indivíduos Padrão I. Em um extremo estariam os indivíduos dolicofaciais, que apresentam uma maior convexidade facial devida à rotação da mandíbula para baixo e para trás, e do outro os braquifaciais, possivelmente portadores dos perfis mais retos entre os indivíduos Padrão I.

\section{Ângulo de convexidade facial total}

O ângulo de convexidade facial total, que avalia a contribuição do nariz na convexidade da face, apresentou média de $137,85^{\circ} \pm 4,08^{\circ}$, mínimo de $129,5^{\circ}$ e máximo de $147,5^{\circ}$, novamente semelhante ao padrão de normalidade da literatura $\left(139^{\circ}\right)$. Não foi observada diferença entre os gêneros.
Fazem-se aqui as mesmas observações em relação à grande variabilidade da medida obtida em portadores de equilíbrio facial. E nesse ângulo, além da influência da posição ântero-posterior da glabela, soma-se a projeção anterior do nariz, estrutura anatômica importante na classificação estética do perfil ${ }^{17}$. Observamos em estudo anterior que aqueles que apresentam uma maior convexidade facial, devida à projeção anterior do nariz, têm seu perfil considerado esteticamente mais desagradável por uma amostra de avaliadores composta por leigos, artistas e ortodontistas ${ }^{17}$.

Novamente, os indivíduos dolicofaciais tenderiam a apresentar maior convexidade e os braquifaciais a menor convexidade dentro do espectro de pacientes Padrão I.

\section{Ângulo do terço inferior da face}

$O$ ângulo do terço inferior da face permite avaliar a protrusão do mento em relação ao terço médio da face. A avaliação desse ângulo é indispensável no planejamento da correção de discrepâncias esqueléticas sagitais ${ }^{9}$.

A média e o desvio-padrão do ângulo do terço inferior da face foram $103,41 \pm 8,12^{\circ}$, variando entre $88^{\circ}$ e $124^{\circ}$. O valor levemente aumentado 
em relação aos $100^{\circ} \pm 7^{\circ}$, sugeridos como padrão pela literatura, denota tendência de menor projeção do mento nos brasileiros Padrão I.

Esse achado coincide com o observado anteriormente para a amostra original de 100 indivíduos portadores de selamento labial passivo ${ }^{17} \mathrm{e}$ com o observado por Passos Filho ${ }^{15}$ em jovens da mesma região do estado de São Paulo.

Observamos, entretanto, pela avaliação das fotografias, que não só a posição anterior do mento como também a posição do ponto cervical são importantes na determinação dessa medida. Pacientes com acúmulo de gordura na região do ângulo queixo-pescoço têm o ponto cervical deslocado inferiormente, aumentando o valor obtido na medida, sem que isso represente uma retrusão mandibular. Esse achado pode ser observado na figura 4 , ilustrativa do indivíduo que obteve o ângulo mais obtuso da amostra.

Verificamos ainda a presença de dimorfismo sexual para essa variável. A média e o desvio-padrão obtidos foram $100,37^{\circ} \pm 6,90^{\circ}$ para o gênero feminino e $108,80^{\circ} \pm 4^{\circ}$ para o masculino. Os resultados sugerem maior protrusão do mento no gênero feminino, entretanto verificamos pela avaliação dos ângulos de convexidade que essa protrusão não se reflete em menor convexidade da face das mulheres.
Novamente, as considerações em relação à posição da glabela, do nariz e do ponto cervical podem ser responsáveis por estas contradições.

\section{Proporção entre Altura Facial Anterior Média e Altura Facial Anterior Inferior (AFAM/AFAI)}

A proporção AFAM/AFAI permite comparar as alturas dos terços médio e inferior da face. É consenso na literatura ortodôntica que a harmonia e o equilíbrio do perfil facial estão associados a um comprimento semelhante desses terços, resultando em um valor de $1 \pm 0,08$ para essa proporção $0^{2,9,22}$.

Observamos, nessa amostra, média e desviopadrão de 0,93 $\pm 0,10$, com o mínimo de 0,80 e o máximo de 1,21, denotando uma tendência dos brasileiros, adultos, leucodermas, equilibrados, apresentarem um excesso do terço inferior em relação ao terço médio da face.

A variabilidade obtida para essa medida entre os valores mínimo e máximo reforça a afirmação de que faces com diferentes relações anatômicas entre as estruturas podem, ainda assim, ser equilibradas.

Observamos dimorfismo sexual nessa variável, com valores do gênero masculino significativamente inferiores ao do feminino $(0,97 \pm 0,09$ para o gênero

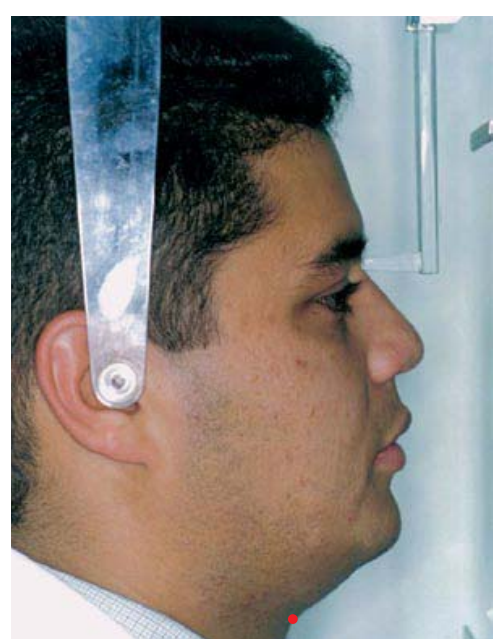

FIGURA 4 - Indivíduo Padrão I portador do ângulo do terço inferior da face mais obtuso da amostra $\left(124^{\circ}\right)$. Observe a posição do ponto cervical.
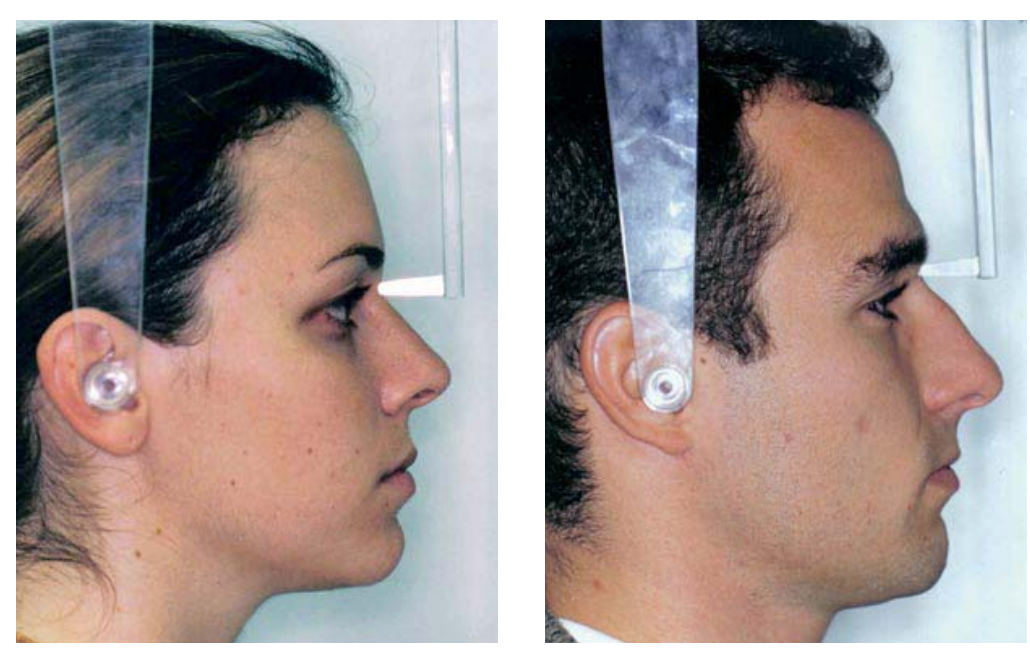

FIGURA 5 - Perfil feminino e o masculino cujos valores apresentaram maior proximidade das médias. 0 perfil feminino foi classificado como esteticamente agradável e o masculino esteticamente aceitável. 
feminino e $0,86 \pm 0,07$ para o masculino). Essa diferença coincide com a observada na amostra total, na qual foi verificado que o responsável pelo dimorfismo era o excesso de AFAI no gênero masculino.

\section{Proporção do terço inferior da face}

Essa proporção avalia o comprimento do lábio superior em relação aos comprimentos somados do lábio inferior e do mento, sendo que o padrão de normalidade descrito na literatura é $0,5(1: 2)^{2,9}$. A proporção do terço inferior da face foi $0,45 \pm$ 0,06 , sem dimorfismo sexual, variando entre 0,30 e 0,67 no perfil facial de brasileiros Padrão I.

Novamente, os resultados revelam uma tendência dos brasileiros portadores de faces equilibradas apresentarem as alturas somadas do lábio inferior e do mento maiores que do lábio superior, quando comparados a leucodermas caucasianos.

\section{CONSIDERAÇÕES FINAIS}

A análise facial numérica, da mesma forma que a cefalometria, auxilia na quantificação de desequilíbrios pela comparação com valores normativos.

Devemos ressaltar, entretanto, a fragilidade dos números em expressar normalidade, pois como observamos nessa amostra de pacientes equilibrados, todas as variáveis apresentaram valores máximos e mínimos distantes da média, sem que isso representasse desarmonia.

A avaliação da face deve ser, portanto, morfológica. Após a verificação da presença da desarmonia, tanto a análise facial numérica quanto a cefalométrica podem ser utilizadas para realizar quantificações em relação à norma, sempre considerando o desvio-padrão.

Os valores normativos a serem utilizados devem ser obtidos em indivíduos Padrão I, portanto equilibrados, de cada população, pois verificamos diferenças na composição facial de latinos, orientais e africanos que não permitem o uso dos valores da literatura internacional, obtidos em leucodermas caucasianos.

A variabilidade dos valores encontrados para as medidas do perfil facial em indivíduos Padrão I pode explicar a distribuição dos mesmos em $6 \%$ esteticamente agradáveis, $92 \%$ esteticamente aceitáveis e 2\% esteticamente desagradáveis.

Por simulação, reduzimos a distância de cada variável de cada indivíduo para uma porcentagem e verificamos aqueles cujas medidas estavam mais distantes ou mais próximos da média. Os perfis esteticamente agradáveis foram o segundo, o décimo nono e o vigésimo quarto mais próximos às médias, enquanto o único perfil esteticamente desagradável da amostra foi o trigésimo segundo mais distante das médias de todas as variáveis. A figura 5 mostra o perfil feminino e o masculino cujos valores apresentaram maior proximidade das médias. O perfil feminino foi classificado como esteticamente agradável e o masculino esteticamente aceitável.

Portanto, o equilíbrio do perfil, que determina o Padrão I, pode estar associado a diferentes desenhos anatômicos do perfil facial. As inúmeras construções possíveis, mesmo no equilíbrio, são responsáveis por valores discrepantes encontrados nas medidas e possivelmente por perda na qualidade da estética facial.

\section{CONCLUSÕES}

Propõe-se, portanto, com o presente trabalho, um conjunto de medidas a ser utilizado como referência para o estudo e avaliação para diagnóstico de indivíduos brasileiros, adultos, leucodermas, portadores de discrepâncias, considerando a média e o desvio-padrão de cada variável estudada.

Verificamos que as médias obtidas diferem na sua maioria dos valores normativos sugeridos pela literatura internacional.

Salientamos, entretanto, que os valores devem ser utilizados com restrições, considerando sua incapacidade de expressar forma, pois observamos que medidas discrepantes podem estar associadas a equilíbrio e que o mesmo valor de uma variável pode estar associado a diferentes desenhos anatômicos do perfil facial. Revisado e aceito: outubro de 2005 


\title{
Numeric facial analysis of the profile in Pattern I Brazilians
}

\begin{abstract}
Aim: the aim of this study was to determine measurements of the facial profile in balanced faces of Pattern I Brazilian patients. Methods: the sample was comprised by 50 Brazilian adults ( 32 women and 18 men) selected by morphologic facial analysis in frontal and lateral views. Standardized lateral facial photographs were taken. They were measured for two different researches to obtain the following: 1) nasolabial angle; 2) angle of mentolabial fold; 3) interlabial angle; 4) angle of facial convexity; 5) angle of total facial convexity; 6) angle of the lower third of the face; 7) proportion between medium facial height and lower facial height; 8 ) proportion of the lower third of the face. Results and Conclusions: there was no statistical difference between the two measurements. The averages, standard deviation, minimal and maximal values obtained were: 1) nasolabial angle: $108.13^{\circ} \pm 9.75^{\circ}\left(81^{\circ}\right.$ to $\left.127^{\circ}\right)$; 2) angle of mentolabial fold: $132.37^{\circ} \pm 9.82^{\circ}\left(110.5^{\circ}\right.$ to $\left.152^{\circ}\right)$; 3) interlabial angle: $135.35^{\circ} \pm 11.14^{\circ}$ $\left(116.5^{\circ}\right.$ to $\left.\left.159.5^{\circ}\right) ; 4\right)$ angle of facial convexity: $12.32^{\circ} \pm 3.93^{\circ}\left(4^{\circ}\right.$ to $\left.\left.19.5^{\circ}\right) ; 5\right)$ angle of total facial convexity: $137.85^{\circ}$ $\pm 4.08^{\circ}\left(129.5^{\circ}\right.$ to $\left.147.5^{\circ}\right) ; 6$ ) angle of lower third of the face: $103.41^{\circ} \pm 8.12^{\circ}\left(88^{\circ}\right.$ to $\left.\left.124^{\circ}\right) ; 7\right)$ proportion between medium facial height and lower facial height: $0.93 \pm 0.10(0.80$ to 1.21$) ; 8)$ proportion of lower third of the face: $0.45 \pm 0.06(0.30$ to 0.66$)$. With those results, we intend to determine values of reference for the measurements of facial profile, establishing averages and standard deviation to be used comparatively in the study and treatment of compromised faces of white Brazilians adults.
\end{abstract}

Key words: Diagnosis. Facial photographs. Facial analysis. Profile.

\section{REFERÊNCIAS}

1. ANGLE, E. H. Classification of malocclusion. Dental Cosmos Philadelphia, v. 41, no. 2, p. 248-265, p. 350-357, Apr. 1899.

2. ARNETT, W. G.; BERGMAN, R. Facial keys to orthodontic diag nosis and treatment planning - Part II. Am J Orthod Dentofacial Orthop, St. Louis, v. 103, no. 5, p. 395-411, May 1993

3. BISHARA, S. E.; HESSION, T. J.; PETERSON, L. C. Longitudinal soft-tissue profile changes: a study of three analyses. Am J Orthod Dentofacial Orthop, St. Louis, v. 88, no. 3, p. 209-223, Sept. 1985

4. BURSTONE, C. J. The integumental profile. Am J Orthod St. Louis, v. 44, no.1, p. 1- 25, Jan. 1958.

5. CAPELOZZA FILHO, L. Diagnóstico em Ortodontia, Maringá: Dental Press, 2004.

6. $\mathrm{CASE}, \mathrm{C} . \mathrm{S}$. A practical treatise on the techniques and principles of dental orthopedia and prosthetic correction of cleft palate. Chicago: C. S. Case, 1921.

7. DOWNS, W. B. Analysis of the dentofacial profile. Angle Orthod, Appleton, v. 26, no. 4, p. 191-212, Oct. 1956.

8. HELLMAN, M. The face and teeth of man. J Dent Res, Chicago, v. 9, no. 2, p. 179-201, 1929

9. LEGAN, H. L.; BURSTONE, C. J. Soft tissue cephalometric analysis for orthognathic surgery. J Oral Surg, Chicago, v. 38, no. 10, p. 744-751, Oct. 1980

10. MARTINS, D. R. Estudo comparativo dos valores cefalométricos das análises de Downs e Tweed, com os de adolescentes brasileiros leucodermas, de origem mediterrânea. Ortodontia, São Paulo, v. 14, n. 2, p. 101-116, maio 1981.

11. MARTINS, L. F. Análise fotométrica em norma frontal de adultos, brasileiros, leucodermas, não tratados ortodonticamente, classificados pela estética facial. 2001. $159 \mathrm{f}$. Dissertação (Mestrado em Ortodontia)-Faculdade de Odontologia, Universidade Metodista de São Paulo, São Bernardo do Campo, 2001.

12. MORESCA, C. A. Ângulo nasolabial. Ortodontia Paranaense, Curitiba, v. 15, n. 1, p. 15-23, jan./jun. 1995

13. MORRIS, W. An orthodontic view of dentofacial esthetics. Compend Contin Educ Dent, Lawrenceville, v. 15, no. 3, p. 378-390, 1994.

14. PARK, Y. C.; BURSTONE, C. J. Soft - tissue profile - Fallacies of hard: tissue standards in treatment planning. Am J Orthod Dentofacial Orthop, St. Louis, v. 90, no. 1, p. 52-62, July 1986.
15. PASSOS FILHO, L. P. Estudo da estética do perfil mole facial em adolescentes brasileiros, leucodermas, com oclusão normal, empregando a análise de Legan e Burstone. 1995. $95 \mathrm{f}$ Dissertação (Mestrado)-Faculdade de Ciências Biológicas e da Saúde do Instituto Metodista de Ensino Superior, São Bernardo do Campo, 1995.

16. RECHE, R. Análise do perfil facial feminino adulto jovem esteticamente agradável em fotografias padronizadas. 1999. Trabalho de Conclusão de Curso (Especialização)-Escola de Aperfeiçoamento Profissional da Associação Brasileira de Odontologia, Curitiba, 1999.

17. REIS, S. A. B. Análise facial numérica e subjetiva do perfil e análise da relação oclusal sagital em brasileiros, adultos, leucodermas, não tratados ortodonticamente. 2001. $271 \mathrm{f}$. Dissertação (Mestrado em Ortodontia)- Faculdade de Odontologia, Universidade Metodista de São Paulo, São Bernardo do Campo, 2001

18. REIS, S. A. B.; CAPELOZZA FILHO, L. C.; CARDOSO, M. A.; SCANAVINI, M. A. Características cefalométricas dos indivíduos Padrão I. R Dental Press Ortodon Ortop Facial, Maringá, v. 10, n. 1, p. 67-78, jan./ fev. 2005.

19. SCHEIDEMAN, G. B.; BELL, W. H.; LEGAN, H. L.; FINN, R. A.; REISCH, J. S. Cephalometric analysis of dentofacial normals. Am J Orthod, St. Louis, v. 78, no. 4, p. 404-420, Oct. 1980.

20. SKINAZI, G. L. S.; LINDAUER, S. J.; ISAACSON, R. J. Chin, nose and lips normal ratios in young men and women. Am J Orthod Dentofacial Orthop, St. Louis, v. 106, no. 5, p. 518-523, Nov. 1994.

21. SUTTER, R. E.; TURLEY, P. K. Soft tissue evaluation of contemporary Caucasian and African American female facial profile. Angle Orthod, Appleton, v. 68, no. 6, p. 487-496, 1998.

22. WOLFORD, L. M. HILLIARD, F. H. The surgical-orthodontic correction of vertical dentofacial deformities. J Oral Surg, Chicago, v. 39 , no. 11, p. 883-897, Nov. 1981

23. WUERPEL, E. H. Ideals and idealism. Angle Orthod, Appleton, v. 1, p. $14-31,1931$.

Endereço de correspondência

Silvia Augusta Braga Reis

Rua Timbiras 1.560 sala 308 - Bairro Lourdes

CEP: 30.140-061 - Belo Horizonte/MG

E-mail: silvia@ortoadultos.com.br 